\title{
Preliminary evaluation of a hydrophilic microfiltration membrane in treating high strength wastewater
}

\begin{abstract}
In this study, two types of flat sheet membranes were produced and tested in the laboratory. These types of membranes are hydrophilic and hydrophobic flat sheet membranes. The membranes were prepared using a phase-inversion technique. Three synthetic based polymers were used to produce the membrane. These polymers are polysulfone (PSF), polyethylene glycol (PEG), and N-methyl- 2-pyrrolidone (NMP). Fourteen polymer solutions were formulated by Response Surface Method and the polymers concentrations used were $15 \mathrm{wt} \%$ for PSF, 30-40 wt \% for PEG and 45-55 wt \% for NMP. The produced membranes were physically characterized by scanning electron microscope (SEM) measurements of their top surface and cross-section images. The produced membranes are used to test the flux value for pure water, synthetic wastewater and raw wastewater using a bench scale unit. Meanwhile, the rejection performance is evaluated using synthetic wastewater and raw wastewater. The pure water flux for the hydrophobic membrane ranges from $78.45 \mathrm{~L} / \mathrm{m} 2 \mathrm{~h}$ to $88.05 \mathrm{~L} / \mathrm{m} 2 \mathrm{~h}$, while pure water flux for the hydrophilic membrane ranges from $41.92 \mathrm{~L} / \mathrm{m} 2 \mathrm{~h}$ to 52.25 $\mathrm{L} / \mathrm{m} 2 \mathrm{~h}$. Meanwhile, the COD rejection rate from raw wastewater was greater for the hydrophilic membrane (58\%) compared to the hydrophobic membrane (42\%). Results obtained from the bench scale unit show a gradual increase in the percentage removal of COD, BOB and TOC with time and it increased from 0 to $75 \%$ from the 1 st day to the 8 th day while only a $20 \%$ increment was observed from the 8th day up to the end of the test. But, the percentage removal obtained form hydrophilic membrane is slightly higher than the percentage removal of the hydrophobic membrane.
\end{abstract}

Keyword: Membrane; Hydrophilic; Hydrophobic; Production; Testing 